\title{
Transcatheter arterial embolization for upper gastrointestinal tract bleeding
}

\author{
Audrius Širvinskas ${ }^{1}$, Edgaras Smolskas², Kipras Mikelis² ${ }^{2}$ Vilma Brimiené ${ }^{3}$, Gintautas Brimas $^{4}$ \\ ${ }^{1}$ Department of Interventional Radiology, Republic Vilnius University Hospital, Vilnius, Lithuania \\ ${ }^{2}$ Faculty of Medicine, Vilnius University, Vilnius, Lithuania \\ ${ }^{3}$ Department of Surgery, Vilnius University Hospital Santariskiu Klinikos, Vilnius, Lithuania \\ ${ }^{4}$ Center of General Surgery, Faculty of Medicine, Vilnius University, Vilnius, Lithuania
}

Videosurgery Miniinv 2017; 12 (4): 385-393

DOI: https://doi.org/10.5114/wiitm.2017.72319

\begin{abstract}
Introduction: Transcatheter arterial embolization is a possible treatment for patients with recurrent bleeding from the upper gastrointestinal tract after failed endoscopic management and is also an alternative to surgical treatment. Aim: To analyze the outcomes of transcatheter arterial embolization and identify the clinical and technical factors that influenced the rates of morbidity and mortality.

Material and methods: A retrospective analysis was carried out, based on the data of 36 patients who underwent transcatheter arterial embolization for acute nonvariceal upper gastrointestinal bleeding in 2013 to 2015 in our center. An analysis was performed between early rebleeding rates, mortality and the following factors: patient sex, age, number of units of packed red blood cells and packed plasma administered to the patients, length of hospital stay, therapeutic or prophylactic embolization.

Results: The technical success rate of the embolization procedure was 100\%. There were 15 (41.70\%) therapeutic embolizations and 21 (58.3\%) prophylactic embolizations. There was a 77.8\% clinical success rate. Following embolization, 10 (27.80\%) patients had repeated bleeding and 9 (25.0\%) patients died. Significant associations were found between rebleeding and prophylactic embolization $(O R=10.53 ; p=0.04)$ and between mortality and prophylactic embolization $(O R=10.53 ; p=0.04)$ and units of packed red blood cells $(O R=1.25 ; p<0.01)$.

Conclusions: In our experience, transcatheter arterial embolization is a safe treatment method for acute nonvariceal upper gastrointestinal bleeding and a possible alternative to surgery for high-risk patients.
\end{abstract}

Key words: gastrointestinal, hemorrhage, transcatheter arterial embolization.

\section{Introduction}

Nonvariceal upper gastrointestinal bleeding is a hemorrhage from the distal esophagus, stomach and duodenum and it still is a major medical emergency problem [1, 2]. The most common cause of such bleeding is a complication of peptic ulcer disease; however, gastroduodenal erosions, MalloryWeiss tears, vascular malformations and tumors are also frequent causes. Although the incidence of peptic ulcer disease is decreasing, the hospitalization and mortality rates of upper gastrointestinal bleeding remain high, especially among the elderly - 20-30 deaths per 100000 patients over the age of 65 years $[3,4]$. The main factors that have been identified as having a negative effect on mortality in cases of upper gastrointestinal bleeding are concomitant illness, elderly age and the use of

\footnotetext{
Address for correspondence

Kipras Mikelis, Faculty of Medicine, Vilnius University, 21 M. K. Čiurlionio St, LT-03101 Vilnius, Lithuania, phone: +37 061149535 ,

e-mail: kiprasmikelis@gmail.com
} 
non-steroidal, anti-inflammatory drugs [5]. Early endoscopy is the recommended method of choice for confirming the diagnosis and treatment of upper gastrointestinal bleeding and is effective at achieving hemostasis in the majority of patients using thermocoagulation, clips, a sclerotherapy agent and injections with epinephrine [6-9]. However, bleeding persists even after successful endoscopic treatment in $10-15 \%$ of cases, and those patients are usually treated surgically, though, according to NICE guidelines, percutaneous embolization as salvage therapy can be recommended [6, 10-14]. Transcatheter arterial embolization (TAE), introduced by Rosch et al. in 1972 as an alternative to surgery for upper gastrointestinal bleeding, has been used as a diagnostic and therapeutic tool, usually reserved for patients who are at high risk for surgery [15-19]. Currently, there is limited research on the outcomes following TAE for upper gastrointestinal bleeding [20, 21].

\section{Aim}

We performed a retrospective analysis of the patients who underwent TAE for nonvariceal upper gastrointestinal bleeding at our hospital. Our purpose was to identify the clinical and technical factors that influenced the outcome of transcatheter embolotherapy and quantify the impact of those variables on morbidity and mortality rates.

\section{Material and methods}

The study was approved by the institutional review board of our hospital. Thirty-six patients with acute nonvariceal upper gastrointestinal bleeding, who were treated with TAE between November 2013 and November 2015, were retrospectively evaluated in the study. The diagnosis was confirmed by endoscopy for all the patients. Cases of gastroduodenal ulcer bleeding were classified according to the Forrest classification. Patients with coagulation disorders had their coagulopathy corrected. Patients with variceal, posttraumatic, or iatrogenic causes of upper gastrointestinal bleeding were excluded.

All of the 36 patients had clinical signs of rebleeding after initial conservative medical therapy and endoscopic treatment with adrenaline (1: 10 000) injections: blood from the nasogastric tube, low blood pressure, an increase in pulse and a low hemoglobin count. A transfemoral approach was used in a standard manner in all cases of an angiographic procedure. A 5 - Fr $11 \mathrm{~cm}$ sheath introducer (CORDIS or TERUMO) was placed in the right or left common femoral artery with the Seldinger technique. Selective angiography of the celiac trunk and superior mesenteric artery was obtained using a 5-Fr catheter (TERUMO Cobra/Simmons-sidewinder or COOK MEDICAL Slip-Cath C1/VS2) in all of the patients. Superselective angiography of the branches of the celiac trunk and superior mesenteric artery was performed using a microcatheter (TERUMO Progreat 2.7 Fr or COOK MEDICAL Cantata 2.7 Fr). Ultravist $240 \mathrm{mg} / \mathrm{ml}$ was used as the contrast medium. Embolization, which was performed after the visualization of contrast extravasation at angiography, was referred to as "therapeutic embolization". In cases where endoscopy visualized a potential site of bleeding, but there was no contrast extravasation during angiography, "prophylactic embolization" was performed. Embolization was carried out with placement of vascular 0.018" TERUMO Azurl; 0.018" COOK MEDICAL Nester or 0.015" BALT Cirrus pushable coils. No embolic agents, other than coils, were used.

In cases of gastroduodenal bleeding from the stomach fundus or corpus, the left gastric artery (LGA) was selectively embolized. If the bleeding site was in the antrum of the stomach, duodenum or of pancreatic origin, the gastroduodenal artery (GDA) was selectively embolized on both sides of the bleeding site to prevent a "back-door" effect - repeated bleeding related to retrograde perfusion. In several cases with bleeding from the liver, a pseudoaneurysm or pancreatic pseudocysts, the hepatic artery or splenic artery was embolized. Postembolization angiography was performed to confirm the effect of embolization in all of the patients.

A retrospective analysis with a review of medical records was performed. Demographic data, clinical findings, endoscopic treatment protocols, the amount of blood transfusion before and after TAE, the length of hospital stay, complications, including recurrent bleeding, the need for surgery after TAE and in-hospital deaths were also analyzed.

\section{Statistical analysis}

We searched for an association of early rebleeding and mortality following embolization with sex, age, time of bleeding, clinical symptoms before embolization, the number of units of blood components transfused and whether the embolization performed was therapeutic or prophylactic. Pearson's 
Table I. Patients characteristics

\begin{tabular}{|lc|}
\hline Parameter & Value \\
\hline Male, $n(\%)$ & $27(75.0)$ \\
\hline Female, $n(\%)$ & $9(25.0)$ \\
\hline Age [years] & $66 \pm 17.13$ \\
\hline Time from bleeding start to TAE [days] & $4.5 \pm 8.2$ \\
\hline Total units of packed red cells & $11.75 \pm 7.30$ \\
\hline Units of packed red cells before TAE & $7.7 \pm 4.67$ \\
\hline Total units of packed plasma & $5.97 \pm 6.18$ \\
\hline Units of packed plasma before TAE & $3.9 \pm 4.14$ \\
\hline
\end{tabular}

TAE - transcatheter arterial embolization.

$\chi^{2}$ test was used to test for an association between categorical data and an independent-samples $t$-test for continuous variables. These variables were then included in a binary logistic regression model. The significance level was set at 0.05 . Data processing was done using SPSS 20.0 software.

\section{Results}

Of the 36 patients who underwent TAE, 27 (75\%) were men and $9(25 \%)$ women. The mean age of the patients was 66 years, ranging from 30 to 100 years. The mean time that passed from the clinical symptoms of bleeding to embolization was 4.5 days, ranging from 0.3 to 49 days. Prior to embolization, 7 patients underwent computed tomography angiography (CTA). For 1 patient, TAE was performed after failed endoscopic and surgical treatment for bleed-
Table II. Causes of nonvariceal upper gastrointestinal bleeding

\begin{tabular}{|lcc|}
\hline Cause & $N$ & Percentage \\
\hline Gastroduodenal ulcers & 20 & 55.6 \\
\hline Pancreatic pseudocysts & 4 & 11.1 \\
\hline Pancreatic cancer & 3 & 8.3 \\
\hline Dieulafoy's lesions & 3 & 8.3 \\
\hline Gastric cancer & 2 & 5.6 \\
\hline Liver tumor (hemangioma) & 1 & 2.8 \\
\hline Pseudoaneurysm & 1 & 2.8 \\
\hline Osler-Weber-Rendu syndrome & 1 & 2.8 \\
\hline Gastroduodenal erosions & 1 & 2.8 \\
\hline Total & 36 & 100.0 \\
\hline
\end{tabular}

ing from a pseudocyst, caused by acute necrotic pancreatitis. Patient characteristics and the amount of packed red blood cells and freshly frozen plasma administered to the patients are presented in Table I.

The causes of bleeding are presented in Table II. The most common causes of bleeding were bleeding from gastroduodenal ulcers (20 cases, 55.6\%), followed by bleeding from pancreatic pseudocysts (4 cases, $11.1 \%$ ), bleeding from pancreatic cancers (3 cases, 8.3\%), Dieulafoy's lesions (3 cases, 8.3\%) and gastric cancers (2 cases, $5.6 \%$ ).

The technical success rate of the embolization procedure, which was defined as complete angiographic occlusion of the targeted vessels, was 100\%.

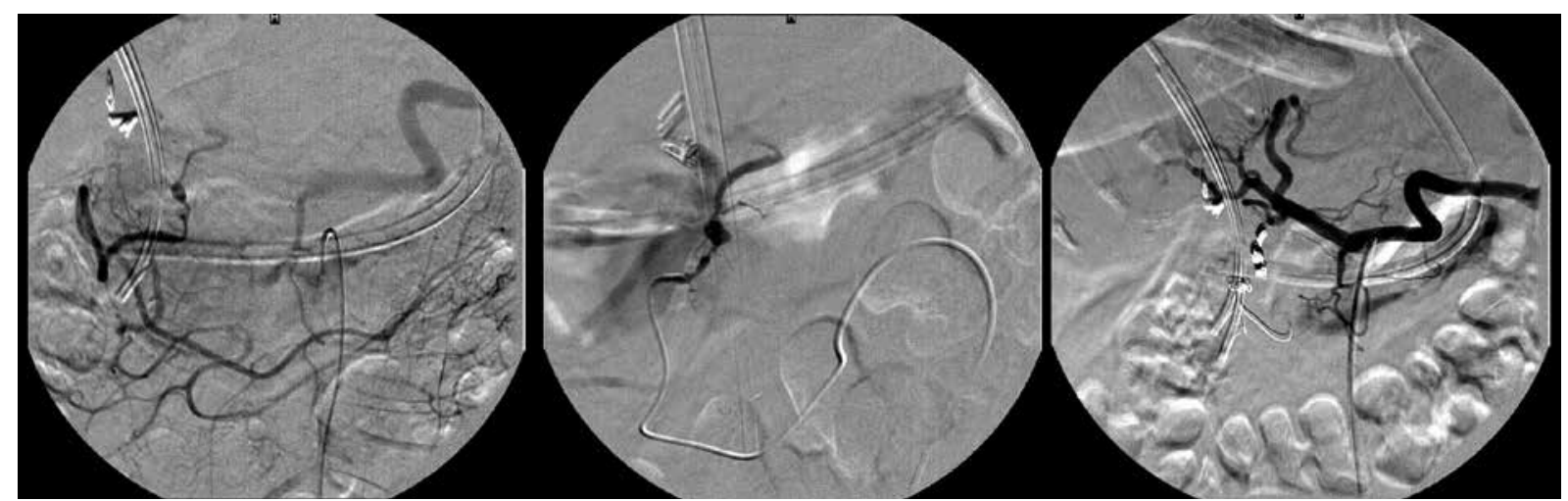

Photo 1. Example of gastroduodenal artery embolization on both sides of the bleeding. A 67-year-old woman with bleeding from a duodenal ulcer. A gastroduodenal artery pseudoaneurysm is visible during the angiography which is a certain source of bleeding. The embolization was performed from two sides - the source was approached via the common hepatic artery and via a branch of the superior mesenteric artery to prevent retrograde bleeding. No ischemic complications were reported 

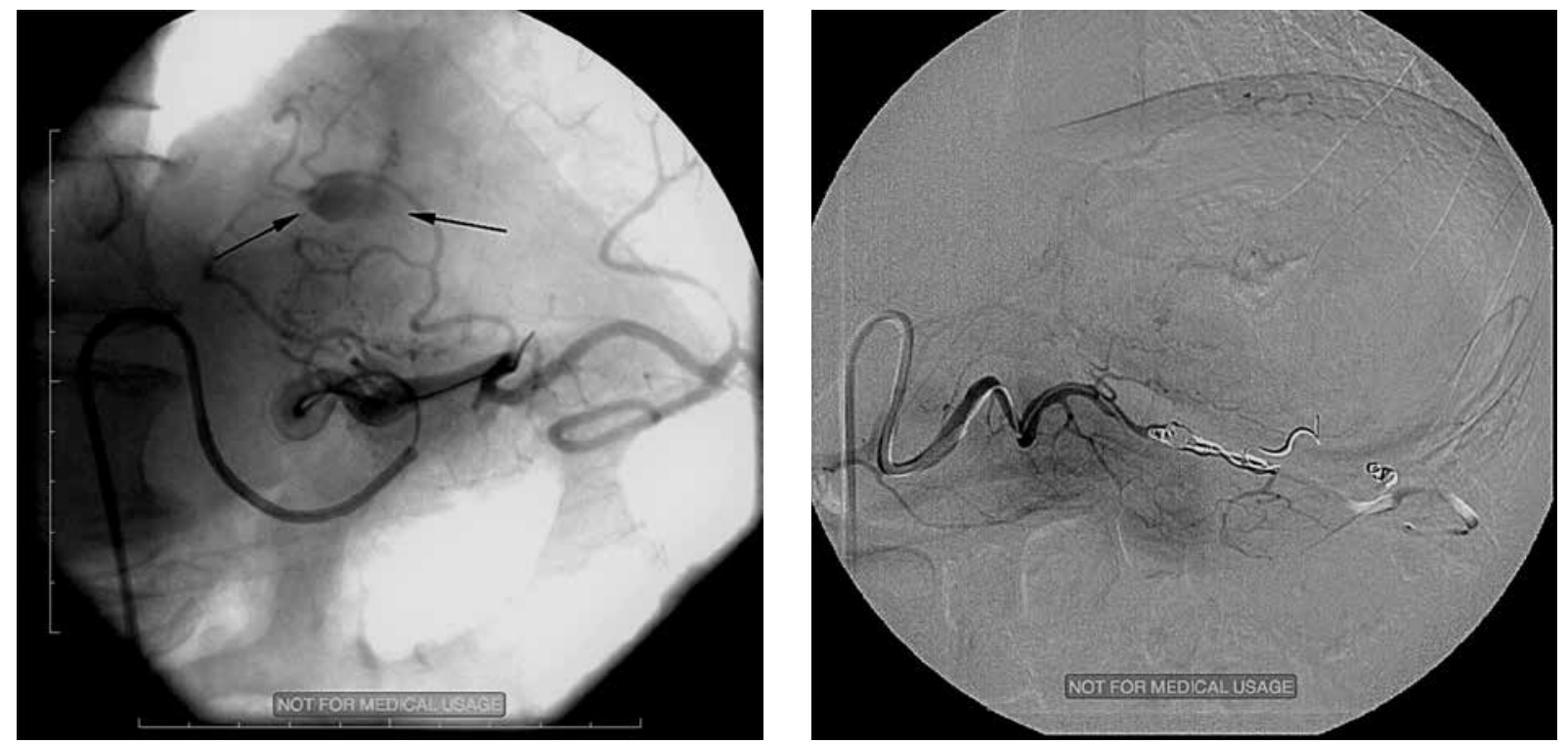

Photo 2. Gastric bleeding originating from a lienal artery branch, supplies blood to the upper third of the stomach. After selective embolization of the branch, bleeding persisted and it was decided to perform embolization of the lienal artery. Bleeding was controlled, no ischemic complications reported

Out of the 36 cases, 15 (41.7\%) were therapeutic embolizations, when the source of the bleeding was visualized during angiography, and 21 (58.3\%) were prophylactic embolizations of the anatomical site.

Table III. Procedural outcomes

\begin{tabular}{|lcc|}
\hline Outcome & $N$ & Percentage \\
\hline Prophylactic embolization & 21 & 58.3 \\
\hline Therapeutic embolization & 15 & 41.7 \\
\hline Technical success & 36 & 100 \\
\hline Clinical success & 28 & 77.8 \\
\hline
\end{tabular}

Table IV. Sites of TAE

\begin{tabular}{|lcc|}
\hline Arteries embolized & N & Percentage \\
\hline Gastroduodenal artery & 27 & 75.0 \\
\hline Splenic artery & 3 & 8.3 \\
\hline Hepatic artery & 2 & 5.6 \\
\hline Left gastric artery & 2 & 5.6 \\
\hline $\begin{array}{l}\text { Gastroduodenal artery } \\
\text { and left gastric artery }\end{array}$ & 1 & 2.8 \\
\hline $\begin{array}{l}\text { Gastroduodenal artery } \\
\text { and right gastroepiploic artery }\end{array}$ & 1 & 2.8 \\
\hline Total & 36 & 100.0 \\
\hline
\end{tabular}

Two examples of the procedure are shown in Photos 1 and 2. The clinical success rate, which was defined as the absence of complications relating to the embolization procedure or rebleeding within 30 days after TAE, was $77.8 \%$. The summarized TAE procedure outcomes are shown in Table III.

The sites of embolization are presented in Table IV. The gastroduodenal artery was targeted most often - in 27 (75\%) cases. Other common sources of bleeding were the splenic artery (3 cases, 8.3\%), hepatic artery (2 cases, 5.6\%) and left gastric artery (2 cases, 5.6\%).

No complications were reported after the procedure. Ten (27.8\%) patients had an episode of rebleeding within 30 days after the embolization procedure, $5(13.9 \%)$ patients after TAE were treated surgically, and the rest received endoscopic treatment.

Nine $(25.0 \%)$ of the patients died (Table V). Out of 9 deaths, 5 patients died without signs of rebleeding after embolization due to comorbidities (pulmonary diseases, ischemic heart disease, cancer intoxication). Four patients died after the surgical procedure because of rebleeding after TAE (2 patients with pancreatic cancer, 1 with acute pancreatitis and 1 with a bleeding duodenal ulcer).

There was no statistically significant association of rebleeding and patient age, sex, cause and site of bleeding or time until hospitalization. After per- 
forming a binary logistic regression analysis of our data, a significantly increased risk of rebleeding after TAE was found in the prophylactic TAE group as compared with therapeutic TAE (Table VI). Five cases of rebleeding after TAE were managed endoscopically and 5 patients had operations. A logistic regression analysis showed an increased risk of mortality that was significantly associated with prophylactic embolization and the total number of units of transfused red blood cells (Table VII).

\section{Discussion}

Recent research supports the claim that TAE is a safe treatment method for gastrointestinal bleeding. Authors have reported satisfactory results of TAE compared to surgery for treatment of bleeding after gastric cancer resection, duodenal bleeding, severe bleeding of upper gastrointestinal tumors and bleeding gastroduodenal ulcers [22-26]. However, surgery was reported to be superior to TAE when treating gastrointestinal bleeding related to gastrointestinal lymphoma, as most of the cases of rebleeding occurred at new sites and ischemic bowel complications proved to be possible after repeated TAE treatment [27]. Research results on the technical aspects of TAE have recently been published - Morishita et al. had success using the "balloon blocking" technique for superselective catheterization under balloon occlusion at the branching site of the target artery, and a systematic review and meta-analysis
Table V. Posttreatment outcomes

\begin{tabular}{|lc|}
\hline Outcome \\
\hline Mean hospital stay [days] & $14.44 \pm 8.94$ \\
\hline 30-day rebleeding, $n(\%)$ & $10(27.80)$ \\
\hline Surgical treatment after TAE, $n(\%)$ & $5(13.89)$ \\
\hline Mortality, $n(\%)$ & $9(25.0)$ \\
\hline
\end{tabular}

by Kim et al. found that embolization using N-butyl cyanoacrylate (NBCA) is effective for gastrointestinal bleeding [28, 29].

Endoscopic therapy is the recommended treatment of upper gastrointestinal bleeding [6, 30]. Uncontrolled bleeding is still frequent, even though early endoscopy reduced mortality rates and repeated bleeding episodes. In the case of rebleeding, emergency surgery was classically considered as the treatment of choice; however, nowadays it is recommended to perform a second therapeutic endoscopy $[31,32]$. A randomized control trial published by Lau et al. showed no difference in outcomes between a second endoscopy and emergency surgery to control upper gastrointestinal bleeding [33]. The vast majority of patients afflicted with bleeding from the upper gastrointestinal tract respond well to conservative treatment or endoscopy [34]. However, when conservative measures fail, percutaneous TAE is accepted for the treatment of upper GI hemorrhage, which is resistant to endoscopic intervention [6, 10-

Table VI. Factors associated with rebleeding within 30 days

\begin{tabular}{|lccc|}
\hline Variable & OR & $95 \% \mathrm{Cl}$ & $P$-value \\
\hline Prophylactic embolization & 10.53 & $1.16-99.01$ & 0.04 \\
\hline Sex & 1.47 & $0.25-8.69$ & 0.67 \\
\hline Bleeding time before hospitalization & 0.94 & $0.76-1.15$ & 0.57 \\
\hline Age & 0.99 & $0.95-1.03$ & 0.66 \\
\hline Units of packed red blood cells & 1.1 & $0.98-1.22$ & 0.08 \\
\hline
\end{tabular}

Table VII. Factors associated with mortality after embolization

\begin{tabular}{|lccc|}
\hline Variable & OR & $95 \% \mathrm{Cl}$ & $P$-value \\
\hline Prophylactic embolization & 10.53 & $1.15-99.01$ & 0.04 \\
\hline Time until hospitalization & 1.18 & $0.91-1.53$ & 0.21 \\
\hline Age & 0.99 & $0.98-1.09$ & 0.68 \\
\hline Units of packed red blood cells & 1.25 & $1.07-1.46$ & $<0.01$ \\
\hline
\end{tabular}


14]. Transcatheter arterial embolization is preferred to surgery in elderly and other high-risk patients, because it is not as invasive as surgery and has few complications [18]. A systematic review conducted by Beggs et al. found no differences in mortality when comparing TAE and surgery, although surgery had lower rebleeding rates [20]. However, the study was subject to multiple sources of bias - most of the studies were retrospective cohort analyses with a certain selection bias (patients with greater comorbidities were selected for TAE) and no randomized studies were found.

Elderly age, recurrent bleeding and concomitant illness are known negative prognostic factors in patients with upper gastrointestinal bleeding $[31,35]$. In a literature review conducted by Loffroy et al., which analyzed 15 retrospective studies of case series of TAE for acute nonvariceal gastrointestinal bleeding, the mean age of the patients presented was 65 years [21]. Most of the patients in our study were of advanced age; the mean age of our patients was 66 years, which is the same as the mean age presented in the review. In most cases, bleeding in our patients was caused by peptic ulcer disease (55.6\%). Bleeding from a gastric or duodenal ulcer is reported to be the most common cause of upper gastrointestinal bleeding: $50 \%$ of all cases reported in the literature are attributed to peptic ulcer disease [36]. Another frequent origin of bleeding in our study was from pancreatic pseudocysts (11.1\%) or a pancreatic tumor (8.3\%). Pancreatic origin of acute gastrointestinal bleeding is generally rare and there are limited epidemiological data to date about its frequency. Pancreatic pseudocysts form in 10\% of cases of acute pancreatitis and $25 \%$ in chronic pancreatitis, whereas bleeding in acute pancreatitis occurs in $1 \%$ of patients $[37,38]$. Most commonly, pseudocysts have intracystic bleeding or bleed into the pancreatic duct; however, a pseudoaneurysm may form because of autodigestion of the arterial wall by pancreatic enzymes and rupture into the cyst or the surrounding hollow viscera [38]. Loffroy et al. reported successful management of bleeding of pancreatic origin using TAE in a small retrospective study and highlighted the advantages of the procedure more accurate localization, easier approach, assessment of collateral flow and lower risk compared with surgery [39]. Bleeding, as a symptom of pancreatic cancer, occurs in $2.6 \%$ of pancreatic cancer patients [40]. Although rare, once pancreatic tumor bleed- ing has occurred, it often repeats and causes major blood loss [41]. This is evident in our data, as two of the three patients with bleeding due to pancreatic cancer had repeated bleeding. It is important to note that the retrospective study design and small patient sample are possible biases of our study. Another study limitation related to the small group size was the inability to analyze several tracked variables, such as bleeding cause and source of bleeding. The retrospective study design limited the variables that may have been related to rebleeding and mortality rates, for example, concomitant illness or coagulation disorders.

An important technical factor in the embolization procedure is the choice of the embolic agent. Coils, a gelatin sponge, polyvinyl alcohol (PVA), N-butyl 2-cyanoacrylate glue (NBCA) and ethylene-vinyl alcohol copolymer are popular options. However, the question of which embolic material is best is still debatable [36]. Coils and microcoils of various size and length have the advantage of low risk of infarction, because they preserve the microvasculature and they may be detachable and retrievable. However, since coils are dependent upon vessel diameter and intrinsic clotting properties, some studies have shown better results and lower rebleeding rates when using coils in combination with a gelatin sponge or PVA in patients with coagulopathy $[42,43]$. A gelatin sponge has the advantage of being cheap, being associated with a low risk of ischemic complications and being resorbable. However, the use of a gelatin sponge alone is associated with higher rebleeding rates in some studies $[44,45]$. Recent studies have shown promising results when using NBCA for gastrointestinal bleeding [29]. Its advantages are shorter procedure times and low rebleeding rates. NBCA requires careful usage at it carries the risk of infarction and it may polymerize on the catheter tip, leading to embolization of a nontarget vessel [36]. One study also reported a potential risk of duodenal stenosis following NBCA embolization over long periods [46]. Ethylene-vinyl alcohol copolymer has been used in several studies with good results $[47,48]$. It has the advantages of being non-adhesive as well as having high radiopacity and longer solidification time. However, it also has its downsides - it is expensive, may cause a severe vasospasm and may also be excreted with sweat, leading to a smell similar to diabetic ketoacidosis.

The mean rebleeding rate observed in our study (27.8\%) is not much different from that found in the 
literature review by Loffroy et al. (33\%) or in the systematic review by Beggs et al. (25\%) [20, 21]. Aina et al. reported an association between early recurrent bleeding and factors such as patient age, sex, coagulopathy and use of coils alone to stop the bleeding [43]. Loffroy et al. also reported additional clinical factors associated with rebleeding, such as cirrhosis, previous surgery and massive blood loss [21]. We found no significant association of recurrent bleeding within 30 days and these clinical factors in our patients. Although several studies report no difference of outcomes between patients who underwent prophylactic embolization and those who had embolization only after the site of bleeding was located during angiography, the topic of prophylactic embolization remains controversial [21, 42, 43, 49]. In our study, an association was found between early rebleeding and therapeutic or prophylactic embolization. Dempsey et al. reported recurrent bleeding (30\%) after prophylactic gastroduodenal artery embolization [50]. According to some authors, in this case, repeated bleeding could be explained by the abundant collateral circulation of the duodenum, although inaccurate artery selection may also be responsible for higher rebleeding rates when performing a prophylactic embolization [21].

The complications of the TAE procedure reported in the literature are groin hematomas (3-17\%) and contrast-related complications (0.04-12.7\%), such as acute renal failure [36]. Embolization in the upper gastrointestinal tract is considered to be safe due to rich collateral blood circulation in the stomach and duodenum; therefore, ischemic complications are rare in this area. Some studies report ischemic complications in the acute phase (Aina et al. (2.7\%)), whereas Lang et al. reported a $25 \%$ rate of duodenal stenosis in the chronic phase of ischemia following the embolization of terminal vessels $[43,46]$. Liver complications (1.3\%) may range from increased enzymes to liver failure [43]. Our patients did not present with any complications following the procedure due to the technical complications of TAE.

The mortality rate reported in our study is not different from rates reported in the literature $24 \%$ in Beggs et al., 28\% in Loffroy et al.). Factors affecting survival reported by other studies are early recurrent bleeding, coagulopathy, cirrhosis and malignancy [21]. Schenker et al. reported a 96\% mortality rate in patients having several organ system failures who did not respond to embolization and a $31 \%$ mortality in those patients who responded to the treatment. Rescue surgery also has a high mortality rate after failed embolization [51]. Most of the patients who died in our cohort had at least one organ system failure. The factors associated with mortality in our study were prophylactic or therapeutic embolization and the number of units of packed red blood cells transfused. Since prophylactic embolization was associated with higher rebleeding rates, this was most likely the cause of higher mortality in that group. It is possible that $\mathrm{CT}$ angiography before embolization would provide a more accurate assessment of the origin of hemorrhage and result in lower repeated bleeding and mortality rates following blind embolization.

\section{Conclusions}

To conclude, in our experience, TAE is a safe treatment method for acute nonvariceal upper gastrointestinal bleeding and a possible alternative to surgery for high-risk patients. However, the evidence in the scientific literature indicates that further research in this area and prospective randomized control trials are clearly needed to be able to recommend TAE over surgery.

\section{Conflict of interest}

The authors declare no conflict of interest.

\section{References}

1. Laine L, Peterson WL. Bleeding peptic ulcer. N Engl J Med 1994; 331: 717-27.

2. Burke SJ, Golzarian J, Weldon D, et al. Nonvariceal upper gastrointestinal bleeding. Eur Radiol 2007; 17: 1714-26.

3. Boonpongmanee S, Fleischer DE, Pezzullo JC, et al. The frequency of peptic ulcer as a cause of upper-GI bleeding is exaggerated. Gastrointest Endosc 2004; 59: 788-94.

4. Higham J, Kang J, Majeed A. Recent trends in admissions and mortality due to peptic ulcer in England: increasing frequency of haemorrhage among older subjects. Gut 2002; 50: 460-4.

5. Rockall T, Logan R, Devlin H, et al. Incidence of and mortality from acute upper gastrointestinal haemorrhage in the United Kingdom. BMJ 1995; 311: 222-6.

6. Barkun AN, Bardou M, Kuipers EJ, et al. International consensus recommendations on the management of patients with nonvariceal upper gastrointestinal bleeding. Ann Intern Med 2010; 152: 101-13.

7. Laine L, McQuaid KR. Endoscopic therapy for bleeding ulcers: an evidence-based approach based on meta-analyses of randomized controlled trials. Clin Gastroenterol Hepatol 2009; 7: 33-47. 
8. Marmo R, Rotondano G, Piscopo R, et al. Dual therapy versus monotherapy in the endoscopic treatment of high-risk bleeding ulcers: a meta-analysis of controlled trials. Am J Gastroenterol 2007; 102: 279-89.

9. Sung JJ, Tsoi KK, Lai LH, et al. Endoscopic clipping versus in jection and thermo-coagulation in the treatment of bleeding non-variceal upper gastrointestinal bleeding: a meta-analysis. Gut 2007; 56: 1364-73.

10. Schoenberg M. Surgical therapy for peptic ulcer and nonvariceal bleeding. Langenbecks Arch Surg 2001; 386: 98-103.

11. Defreyne L, De Schrijver I, Decruyenaere J, et al. Therapeutic decision-making in endoscopically unmanageable nonvariceal upper gastrointestinal hemorrhage. Cardiovasc Intervent Radiol 2008; 31: 897-905.

12. Kim SK, Duddalwar V. Failed endoscopic therapy and the in terventional radiologist: non-variceal upper gastrointestina bleeding. Tech Gastrointest Endosc 2005; 7: 148-55.

13. Bendix Holme J, Tønner Nielsen D, Funch-Jensen P, et al. Transcatheter arterial embolization in patients with bleeding duodenal ulcer: an alternative to surgery. Acta Radiol 2006; 47: 244-7.

14. Eriksson LG, Ljungdahl M, Sundbom M, et al. Transcatheter arterial embolization versus surgery in the treatment of upper gastrointestinal bleeding after therapeutic endoscopy failure. J Vasc Interv Radiol 2008; 19: 1413-8.

15. Rösch J, Dotter CT, Brown MJ. Selective arterial embolization: a new method for control of acute gastrointestinal bleeding. Radiology 1972; 102: 303-6.

16. Toyoda H, Nakano S, Takeda I, et al. Transcatheter arterial embolization for massive bleeding from duodenal ulcers not controlled by endoscopic hemostasis. Endoscopy 1995; 27: 304-7.

17. Goldman ML, Land Jr WC, Bradley III E, et al. Transcatheter therapeutic embolization in the management of massive upper gastrointestinal bleeding. Radiology 1976; 120: 513-21.

18. Ripoll C, Bañares R, Beceiro I, et al. Comparison of transcatheter arterial embolization and surgery for treatment of bleeding peptic ulcer after endoscopic treatment failure. J Vasc Interv Radiol 2004; 15: 447-50.

19. Schenker MP, Duszak R, Soulen MC, et al. Upper gastrointestinal hemorrhage and transcatheter embolotherapy: clinical and technical factors impacting success and survival. J Vasc Interv Radiol 2001; 12: 1263-71.

20. Beggs AD, Dilworth MP, Powell SL, et al. A systematic review of transarterial embolization versus emergency surgery in treatment of major nonvariceal upper gastrointestinal bleeding. Clin Exp Gastroenterol 2014; 7: 93-104.

21. Loffroy R, Rao P, Ota S, et al. Embolization of acute nonvariceal upper gastrointestinal hemorrhage resistant to endoscopic treatment: results and predictors of recurrent bleeding. Cardiovasc Intervent Radiol 2010; 33: 1088-100.

22. Yang J, Zhang $X$, Huang $Y$, et al. Diagnosis and treatment of abdominal arterial bleeding after radical gastrectomy: a retrospective analysis of 1875 consecutive resections for gastric cancer. J Gastrointest Surg 2016; 20: 510-20.

23. Bagdasarov V, Bagdasarova E, Chernookov A, et al. Endovascular arterial embolization for duodenal bleeding as an alternative to surgical approach. Khirurgiia (Sofiia) 2016; 2: 45-50.
24. Zandrino F, Tettoni S, Gallesio I, et al. Emergency arterial embolization of upper gastrointestinal and jejunal tumors: an analysis of 12 patients with severe bleeding. Diagn Interv Imaging 2017; 98: 51-6.

25. Park S, Shin JH, Gwon DI, et al. Transcatheter arterial embolization for gastrointestinal bleeding associated with gastric carcinoma: prognostic factors predicting successful hemostasis and survival. J Vasc Interv Radiol 2017; 28: 1012-21.

26. Nykänen T, Peltola E, Kylänpää L, et al. Bleeding gastric and duodenal ulcers: case-control study comparing angioembolization and surgery. Scand J Gastroenterol 2017; 52: 523-30.

27. Zheng L, Shin JH, Han K, et al. Transcatheter arterial embolization for gastrointestinal bleeding secondary to gastrointestinal lymphoma. Cardiovasc Intervent Radiol 2016; 39: 1564-72.

28. Morishita H, Takeuchi Y, Ito T, et al. Balloon blocking technique (BBT) for superselective catheterization of inaccessible arteries with conventional and modified techniques. Cardiovasc Intervent Radiol 2016; 39: 920-6.

29. Kim PH, Tsauo J, Shin JH, et al. Transcatheter arterial embolization of gastrointestinal bleeding with $\mathrm{N}$-butyl cyanoacrylate: a systematic review and meta-analysis of safety and efficacy. J Vasc Interv Radiol 2017; 28: 522-31.

30. Sacks HS, Chalmers TC, Blum AL, et al. Endoscopic hemostasis: an effective therapy for bleeding peptic ulcers. JAMA 1990; 264: 494-9.

31. Cochran TA. Bleeding peptic ulcer: surgical therapy. Gastroenterol Clin North Am 1993; 22: 751-78.

32. Williams RA, Vartany A, Davis IP, et al. Impact of endoscopic therapy on outcome of operation for bleeding peptic ulcers. Am J Surg 1993; 166: 712-4.

33. Lau JY, Sung J, Lam Y, et al. Endoscopic retreatment compared with surgery in patients with recurrent bleeding after initial endoscopic control of bleeding ulcers. N Engl J Med 1999; 340: 751-6.

34. Savides TJ, Jensen DM. Therapeutic endoscopy for nonvariceal gastrointestinal bleeding. Gastroenterol Clin North Am 2000; 29: 465-87.

35. Lieberman D, Keller F, Katon R, et al. Arterial embolization for massive upper gastrointestinal tract bleeding in poor surgical candidates. Gastroenterology 1984; 86: 876-85.

36. Loffroy R, Favelier S, Pottecher P, et al. Transcatheter arterial embolization for acute nonvariceal upper gastrointestinal bleeding: indications, techniques and outcomes. Diagn Interv Imaging 2015; 96: 731-44.

37. Andersson E, Ansari D, Andersson R. Major haemorrhagic complications of acute pancreatitis. Br J Surg 2010; 97: 1379-84.

38. Razik R, May GR, Saibil F. Non-operative management of necrotic pancreatic collection and bleeding pseudoaneurysm communicating with bowel lumen at multiple sites: a case report and review of the literature. J Gastrointest Liver Dis 2016; 25: 109-14.

39. Loffroy R, Guiu B, Cercueil JP, et al. Transcatheter arterial embolization of splenic artery aneurysms and pseudoaneurysms: short-and long-term results. Ann Vasc Surg 2008; 22: 618-26.

40. Lee P, Sutherland D, Feller ER. Massive gastrointestinal bleeding as the initial manifestation of pancreatic carcinoma. Int J Gastrointest Cancer 1994; 15: 223-7. 
41. Takada R, loka T, Sueyoshi H, et al. Duodenal hemorrhage from pancreatic cancer infiltration controlled through combination therapy with gemcitabine and S-1. Case Rep Gastroenterol 2014; 8: 221-6.

42. Loffroy R, Guiu B, D'athis P, et al. Arterial embolotherapy for endoscopically unmanageable acute gastroduodenal hemorrhage: predictors of early rebleeding. Clin Gastroenterol Hepatol 2009; 7: 515-23.

43. Aina R, Oliva VL, Therasse É, et al. Arterial embolotherapy for upper gastrointestinal hemorrhage: outcome assessment J Vasc Interv Radiol 2001; 12: 195-200.

44. Lang E, Picus D, Marx M, et al. Massive arterial hemorrhage from the stomach and lower esophagus: impact of embolotherapy on survival. Radiology 1990; 177: 249-52.

45. Encarnacion C, Kadir S, Beam C, et al. Gastrointestinal bleeding: treatment with gastrointestinal arterial embolization. Radiology 1992; 183: 505-8.

46. Lang EK. Transcatheter embolization in management of hemorrhage from duodenal ulcer: long-term results and complications. Radiology 1992; 182: 703-7.

47. Lenhart M, Paetzel C, Sackmann M, et al. Superselective arterial embolisation with a liquid polyvinyl alcohol copolymer in patients with acute gastrointestinal haemorrhage. Eur Radiol 2010; 20: 1994-9.

48. Urbano J, Cabrera JM, Franco A, et al. Selective arterial embolization with ethylene-vinyl alcohol copolymer for control of massive lower gastrointestinal bleeding: feasibility and initial experience. J Vasc Interv Radiol 2014; 25: 839-46.

49. Padia SA, Geisinger MA, Newman JS, et al. Effectiveness of coil embolization in angiographically detectable versus non-detectable sources of upper gastrointestinal hemorrhage. J Vasc Interv Radiol 2009; 20: 461-6.

50. Dempsey DT, Burke DR, Reilly RS, et al. Angiography in poorrisk patients with massive nonvariceal upper gastrointestina bleeding. Am J Surg 1990; 159: 282-6.

51. Welch CE, Rodkey GV, von Ryll Gryska P. A thousand operations for ulcer disease. Ann Surg 1986; 204: 454-67.

Received: 11.05.2017, accepted: 15.08.2017. 